Research Article

\title{
Operational Considerations to Manage Quarantine Facility: Lessons Learnt in Setting-up the First Quarantine Centre in India for Evacuees from Wuhan (The epicentre of COVID- 19 Outbreak), China
}

\author{
Ajit Shewale', Himanshu Vashistha', Rameshwar Sorokhaibam', Meera Dhuria', SK]ain', \\ $\underline{\text { AP Joshi }}{ }^{2}, \underline{\text { Sujeet Singh }}$
}

${ }^{1}$ National Centre for Diseases Control (NCDC), Ministry of Health and Family Welfare (MoHFW), Delhi, India. ${ }^{2}$ Indo Tibetan Border Police Quarantine Center, Chhawla Camp, Delhi, India. DOI: https://doi.org/10.24321/0019.5138.202133

I $\quad \begin{array}{llll}\mathbf{N} & \mathbf{F} & \mathbf{O}\end{array}$

Corresponding Author:

Ajit Shewale, National Centre for Diseases Control (NCDC), Ministry of Health and Family Welfare (MoHFW), Delhi, India.

E-mail Id:

adshewale12527@gmail.com

Orcid Id:

https://orcid.org/0000-0001-8301-5723

How to cite this article:

Shewale A, Vashistha H, Sorokhaibam R, Dhuria $M$, Jain SK, Joshi AP, Singh S. Operational Considerations to Manage Quarantine Facility: Lessons Learnt in Setting-up the First Quarantine Centre in India for Evacuees from Wuhan (The epicentre of COVID-19 Outbreak), China. J Commun Dis. 2021;53(3):1-10.

Date of Submission: 2021-05-08

Date of Acceptance: 2021-09-21
$\begin{array}{lllllllll}\mathbf{A} & \mathbf{B} & \mathbf{S} & \mathbf{T} & \mathbf{R} & \mathbf{A} & \mathbf{C} & \mathbf{T}\end{array}$

Background: On January 30, 2020, the World Health Organization (WHO) declared COVID-19 as a "public health emergency of international concern." In order to contain the outbreak, China used quarantine measures. India was among the first few to evacuate its citizens.

Methods: It is a retrospective cohort study of Indian evacuees who returned from Wuhan, China. Standard operative procedures were developed for daily screening, sample collection, medical management, transport and referral, biomedical waste management, food safety, etc. Lessons learned were incorporated in subsequent trainings to improve effectiveness.

Results: India evacuated 647 nationals including seven Maldivian citizens from Wuhan, China in many batches (with first two batches having 104 and 302 evacuees respectively) during the consecutive days of February 1st and 2nd, 2020. These 2 batches of evacuees including seven Maldivian citizens were stationed at Indo-Tibetan Border Police (ITBP) Chhawla Camp, Delhi; the first quarantine facility in India for novel Coronavirus. Rest of the spassenger were sheltered at a military quarantine facility at Manesar.

Conclusion: Developing standard procedures/checklist for routine activities and effective trainings were key to successful quarantining the evacuees in the initial phase of outbreak of COVID-19.

Keywords: Quarantine, COVID-19, Evacuation, SOPs 


\section{Introduction}

The outbreak of novel coronavirus designated as SARSCOV-2 responsible for the COVID-19 pandemic was initially reported from Wuhan, Hubei Province of China in early December 2019. ${ }^{1}$ It spread sporadically with people moving around the world carrying the highly contagious disease along. The spread was so swift that on January 30,2020 , the World Health Organization (WHO) declared it as a 'public health emergency of international concern' (WHO report on events as they happen, Feb 2020, WHO 2019-nCoV situation report). ${ }^{2}$ In order to contain the outbreak, China used quarantine measures and Wuhan was completely locked down as preventive measures. Looking at the susceptible environment, many countries evacuated their nationals from China. As a response plan for a health emergency, India was among the first few to evacuate its citizens. To limit the community spread, a minimum of 14-day quarantine of all evacuees was made mandatory. In those prevailing situations, India evacuated 647 nationals including seven Maldivian citizens from Wuhan, China in many batches (with the first two batches having 104 and 302 evacuees respectively) during the consecutive days of February 1st and 2nd, 2020. These 2 batches of evacuees including seven Maldivian citizens were stationed at Indo-Tibetan Border Police (ITBP) Chhawla Camp, Delhi; the first quarantine facility in India for novel Coronavirus. Rests of the other passenger were sheltered at a military quarantine facility at Manesar, Haryana, India.

\section{Preparedness Review}

The quarantine facility at ITBP was reviewed by the Public Health Officials of National Centre for Disease Control (NCDC). The facility was thoroughly reviewed keeping in mind the following essential points:

- Location of quarantine centre (i.e. isolated place, out of bound to the general public, no access to animals such as monkeys, dogs, cows, etc.)

- Appropriate $24 * 7$ security

- Facility for separation of individual beds (distance between two beds should be at least 1-2 meters)

- Separate facility for laundry

- Separate facility of food canteen

- Waste disposal and BMW management plan

- Provision of vehicle for transportation of evacuees, ample ambulances ${ }^{4}$

- Fire and electrical safety facility

- Separate sewage treatment plant/Effluent treatment plant (STP/ ETP) facility

- Provision of a control room for administrative meetings and routine monitoring

- Adequate ventilation of quarantine building

NCDC recommended the following: a. Standby ambulances

b. Vehicles for transport of individuals

c. Telecommunication facility

d. Canteen facility for staff

e. Appropriate logistics including Personal protective equipment (PPE) kits with masks, gloves, full closing gowns, shoe covers, and hair covers

f. Sample collection and packaging material with cold chain maintenance

g. Biomedical waste management materials with yellow bags, red bags, black bags, and foot operating dustbins

h. Disinfection material (hypochlorite and absolute alcohol)

i. Surgical material

j. IEC material

All the above recommendations were made as per daily consumption basis.

Further, SOPs for infection Prevention and Control (PPEs, Bio-medical waste management, disinfection), facility and transfer vehicles including an ambulance, movement of personnel posted (health, non-health including housekeeping, catering), clinical management for resident doctors, nursing \& supporting staff security and other logistic teams were established. Representative Standard Operative Procedures ( SOPs) prepared by NCDC team are placed at Annexure (1-4).

\section{Activities Undertaken in Quarantine Facility}

\section{Risk Assessment of the Quarantine Facility}

Risk level refers to the likelihood of any person catching coronavirus at the quarantine site due to movements and activities at the site.

NCDC conducted risk assessment to identify biohazard risk precaution levels along with its associated activities. Areas were split and labelled as:

- Low-risk areas: Areas having less direct contact with evacuee suspects such as control room centre in the quarantine centre, nursing station and areas of the kitchen where food is cooked.

- Moderate-risk areas: Areas where infectious aerosols are expected to be present like laundry with evacuee's bed linen, pillows and nearby cloths. This included a low concentration of infectious particles and contaminated surfaces near quarantine zones.

- High-risk areas (containment quarantine camp): Areas where staff physically interacts with evacuees like the place of conducting a medical examination; areas where high generation of infectious aerosols are expected like evacuees coughing, sneezing, gag reflex during nasopharyngeal \& oropharyngeal sample collection; toilet and bathroom areas, dining areas; and areas of bio-waste collections, segregation and disposal. 
Further, NCDC recommended any new person entering the quarantined building be first inducted in the control room for proper awareness and training on infection control measures; well informed and trained security personnel to check key entry points; round-the-clock guard keeping a record of who's entering and leaving the facility; and a designated nursing officer to ensure proper PPE wear at the entry points of the site. International biohazard warning symbol and sign was made mandatory to be displayed on the doors of the rooms of the evacuees, bio-medical waste management areas and areas where higher risk groups were handled. Only authorized trained persons were to be permitted to enter quarantine areas. All the doors at the facility to be also kept closed at all times under the observation of a guard. Double door entry was mandatory with a one-at-a-time door opening (Figure 1). doing medical examinations and procedures that involved handling of samples. Personal Protective Equipment (PPE) shoe covers, gowns, gloves, goggles, face masks and shields were made available and stocked so that they were easily accessible to all workers at the Quarantine site. Instructions on handwashing were displayed at strategic locations. Washbasins were also made available at the camp building and control building. Staff was trained on how to handle all technical procedures with minimum risk of spills, splashes and production of aerosols. The procedure/ flowchart for clean-up and disposal of all spills was designed and printed to be displayed at key locations on the site. A first aid box was available with adequate medication at the nursing station. The sewage treatment system was separate for the quarantine building and was regularly monitored by the NCDC team for proper functioning.

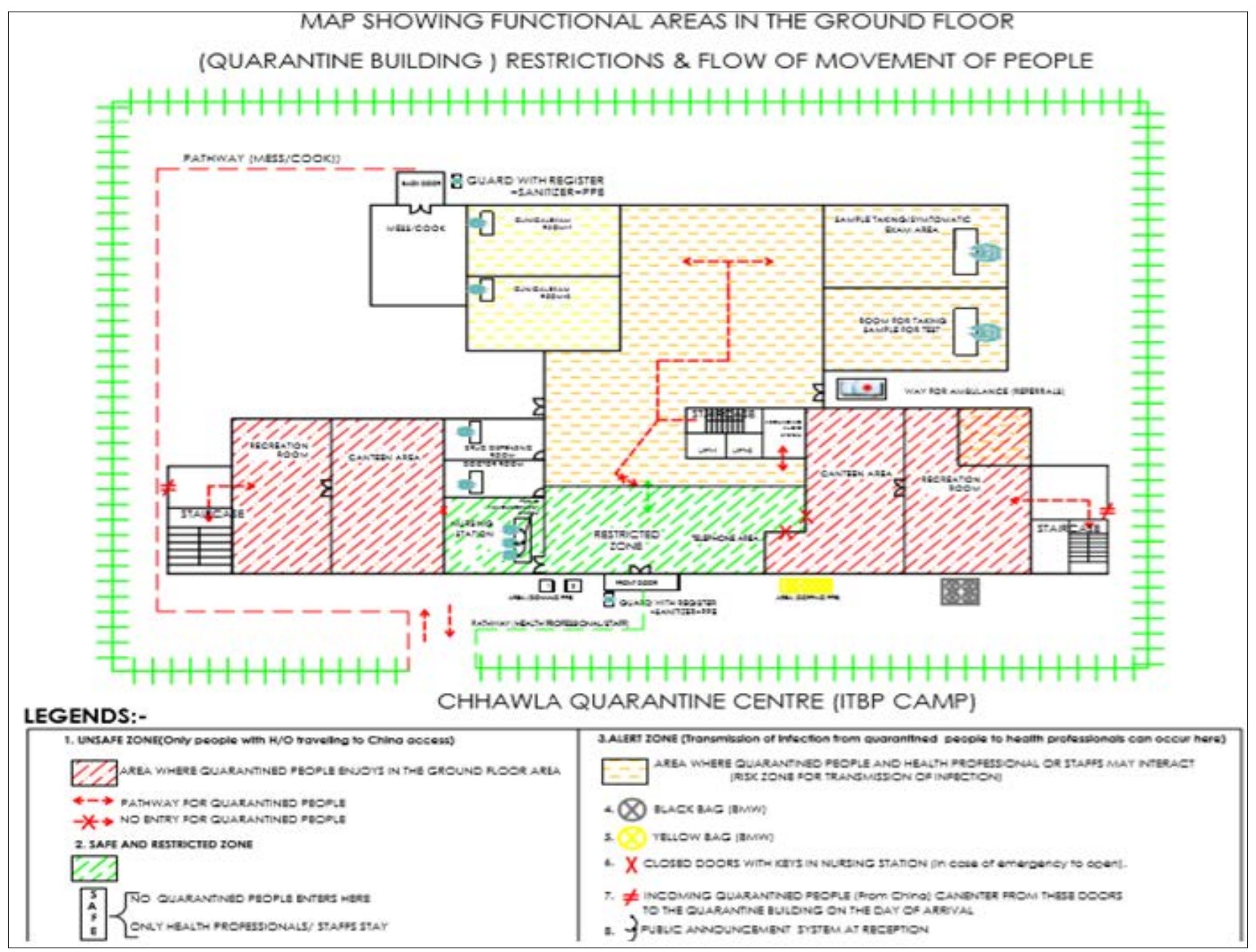

Figure I.Map of Quarantine Facility

NCDC also recommended certain personal practices with a display of information like 'do not eat' discouraging usage of liquor, smoking, chewing gums, lip salve, and contact lenses in the quarantine facility. Neatly tied long hair along with no usage of long flowing clothes was encouraged while
On arrival at the facility, the evacuees were mandated to furnish information on the place of their residence in China, period of stay in China along with demographic and contact details. Unique serial numbers/ admission numbers were allotted to each evacuee for the identification of samples. 
Each family was considered as a separate unit and housed in the 5 -floor building.

There were 214 men, 194 women and 11 children. Since the evacuees were separated as per family unit, intermixing of passengers from different floors were not allowed to curb infection. Passengers were briefed about what to do and what not to do and encouraged to follow hygiene practices like frequent proper handwashing, cough etiquette and self-reporting of any initial symptoms related to COVID-19.

\section{Human Resource Deployment}

Chief Medical Officer (CMO) ITBP was appointed as incharge/ nodal officer of the quarantine facility. 52 clinical doctors including general duty officers, medicine specialists, paediatrics, psychiatrists, and psychologists both from paramilitary organisation and Central Government Hospitals (Indo Tibetan Border Police, Border Security Force, Central Reserve Police Force, Sashatra Seema Bal, All India Institute of Medical Sciences, Safdarjung hospital, Ram Manohar Lohia, Lady Hardinge Medical College) were posted at ITBP camp for routine examination and relevant clinical care of the quarantined people. A team of 3 public health specialists including one microbiologist from NCDC were posted in the facility to undertake public health activities including awareness generation (IEC) to healthcare care professionals/ supporting staff, security personnel and other helping staff at the site. They provided training related to infection prevention control and biosafety measures like donning and doffing of PPE, wearing masks, gloves etc. A team of 24 staff nurses and 27 medics were also posted to assist the clinicians in managing the quarantine facility from different paramilitary (CAPF) organisations and Central Government institutions.

An overall situational analysis and assessment to fully support the purpose of the facility was done by NCDC prior to the arrival of the evacuees. Inputs on the facility like the infrastructure, logistics, awareness level, skills, basic plans for movements in strategic points in the building and area relevant to infection prevention and control, identifying biohazard risk precaution levels were the assessment criteria considered. All staff deployed at the facility were advised for home quarantine for 14 days after completion of the task.

\section{Training}

It was very crucial to train staff to ensure that protocols and SOPs were adhered to. Medical officers and staff were trained for daily examination, movements in the facility, infection prevention control measures and use of PPE kit etc.

Clinicians, laboratory technicians, and medics were trained for sample collection (nasopharyngeal and throat) and triple-layer packaging with cold chain maintenance.
Paramedical staff including nurses, medics, pharmacists etc. were trained on SOPs to be adhered to at the site. Non-paramedic staff was trained on the use of masks, gloves, cleaning and disinfection procedures. Training on the use of PPE kits was mandatory for all.

Refresher training to all the staff was provided on a need basis. In the case of new staff, it was ensured that proper training was given before undertaking any work. All activities/ procedures were done under strict monitoring/ observations of trained specialists.

\section{Daily Clinical Examination and Referral}

All quarantined were clinically examined including thermal scanning twice daily (morning 8 am and evening $6 \mathrm{pm}$ ) and those requiring referrals for related symptoms of Coronavirus (fever, cough, sore throat, breathlessness etc.) or any other reason were referred to Safdarjung hospital, Delhi in an ambulance with due precautions taken during the travel as per referral Standard Operating Procedure. Four ambulances were on standby mode for transport including an advanced life-saving ambulance. During the 14-day quarantine period, a total of 12 cases ( 04 cases with mild symptoms s/o COVID-19, 08 non-COVID-19 related symptoms) were referred. Before discharging suspects were tested for COVID-19 and reported as negative for SARS-COV-2. Later, they were again quarantined for 14 days in the ITBP facility in a separate area dedicated to such high-risk groups.

\section{Coordination}

Chief Medical Officer, CMO (SG), ITBP was in-charge of the quarantine facility and undertook overall coordination and supervision with various organisations (paramilitary and Central Govt. institutions). To ensure all activities take place according to standard protocol and as per NCDC team recommendation, separate teams were constituted for various purposes - supervisory team, admin team, logistic team, referral team, medicine/ equipment team, hygiene sanitation team.

Daily two review meetings were convened under the chairmanship of in-charge $\mathrm{CMO}$ to discuss day-to-day affairs and sort out any issue requiring attention. $24 * 7$ control was established at the ground floor with speakers at each floor so that the quarantined evacuees can be communicated to on a routine basis and necessary instructions can be provided.

\section{Recording and Reporting Mechanisms}

To ensure standardised reporting, daily reporting formats of suspected cases with symptoms related to coronavirus, number of cases requiring referral and sample collection status was designed. It was sent daily to ITBP authorities, NCDC, MoHFW and other relevant higher authorities. 


\section{Monitoring and Supervision}

Daily visits were conducted inside and outside the quarantine facility including in the surrounding campus by the NCDC team and lags were noted to immediately take necessary preventive actions by the nodal officer. Visits were also conducted by senior officers from NCDC, MOHFW, and ITBP for regular review.

\section{Establishment of Infection Prevention Control (IPC) Measures}

Risk assessment was undertaken by the NCDC team with respect to the probability of infection from possibly infected passengers to healthcare staff, other staff, and surrounding areas. A special map of the facility was prepared to outline the details of the movement of staff around the quarantine area and in the building. It was ensured that movement of all staff would be undertaken as per the map designed to prevent and control infections (Figure 1).

As per the recommendation of the NCDC team, a separate green fence was raised around the building to prevent the entry of animals especially dogs, monkeys and even birds if possible. Well informed and trained security personnel were deployed all around the building on a $24 * 7$ rotation basis to monitor the facility and to avoid entry of undesired persons/ animals and even birds for eating any food remains/droppings inside the area.

To ensure that all healthcare personnel use PPE as per guidelines, they were properly trained and assisted during the wearing of PPE. Separate areas were earmarked for PPE donning and doffing. As it was noted that compliance was not adequate in the initial days, instructions for wearing PPE (donning) and doffing were placed at the entrance of the building.

Alternately well informed and trained nursing officers were stationed at the building to regulate the movement of the staff entering the facility. The nursing officer was assigned the duty to ensure essential data like name, designation and entry and exit time were recorded for every person entering the facility. The Nursing officer also ensured that all the persons were labelled while entering the building so that they can be identified by the security staff. At the entrance, two-door entries were ensured to reduce the interaction interface of passengers with healthcare staff.

Initially, the entrance to the canteen and recreational room on the ground floor had a common entry that allowed unnecessary constant interaction between evacuees and healthcare staff. Therefore, common entry to these two rooms was closed and a separate entry for all was ensured.

It was ensured that the complete quarantine facility is decontaminated daily with disinfectants (freshly prepared $1 \%$ hypochlorite, detergent solution) including surface mopping of all the floor, bathrooms, toilets facility, underside of beds, other related items placed in the rooms of evacuees.

As more than 2 people were kept in the rooms, it was suggested that a separate cubicle for people developing mild symptoms for temporary observation (transit room) may be considered for early isolation of any symptomatic person to prevent the transmission to other clusters of groups.

\section{Food, Laundry and Other Related Activities}

As recommended by NCDC separate backdoor entry was created for the entry of canteen staff with all wearing PPE. The buffet was packed as an assortment in one plate for each individual and served. Food containers were disinfected daily. Food menu consisting of morning tea, snack, lunch, evening tea, and dinner was prepared by the ITBP team daily. To avoid cross-infection in the canteen, the NCDC team recommended disposable and pre-packed food. All evacuees were given separate beds that were kept separate with a distance of 1-2 meters with no bed facing opposite to each other. Disposable bed sheets allowed easy change on daily basis. Each evacuee was given toiletries, towel, blanket, pillow with covers, electric kettle, room heater and water dispenser by the ITBP team.

Laundry service was undertaken in a separate building. All washable items were soaked in $1 \%$ hypochlorite for 30 minutes before washing with detergent solution.

\section{Biomedical Waste (BMW) Management}

To ensure that biomedical waste management in the facility takes place as per standard guidelines, separate yellow, red/ black bags and foot operating dustbins were kept on each floor and outside the facility. It was strictly ensured that doffing takes place in the designated area with all the PPE kits including masks, gloves, and these are properly placed in yellow bags. All healthcare workers collecting the possibly infectious material such as food items, PPE kits from yellow bags should also wear PPE and follow the IPC measures. A designated place was earmarked outside the building for the collection of yellow and black bags. It was collected twice daily by a private biomedical waste management vehicle as per the agreement. The site of collection of biomedical waste was then regularly disinfected with freshly prepared $1 \%$ hypochlorite solution. To avoid the unnecessary collection of waste materials in yellow bags outside the building, BMW vehicle authorities were coordinated with by the team. All officials concerned with the camp administration and all other healthcare workers including medical, paramedical, nursing officers, other paramedical staff and waste handlers such as safai karmacharis, attendants, and sanitation attendants were well oriented to the requirements of handling and 
management of general and biomedical waste generated at the camp.

Management of biomedical waste was followed as per the SOP which included all procedure explanations for generation, accumulation, handling, storage, treatment, transport and disposal. So there are no compliance issues, continuous training, monitoring, and supervision were done on daily basis. Waste from the quarantine facility was treated separately as isolation waste by disinfecting it under strict monitoring of specialised health authorities.

\section{Logistic Management}

NCDC along with ITBP purchased the logistics to use at the quarantine facility. PPE, medical equipment including thermal thermometer, stethoscope, BP machine, office logistics, sample collection and packaging material etc. were bought. Performa was prepared for daily consumption of PPE, triple-layer masks, gloves, etc. and monitored by the logistics team on daily basis. Some minor issues like inaccurate size of PPE kits were conveyed to appropriate authorities for necessary corrective action.

\section{Information, Education and Communication (IEC) and Psycho-social Support}

As on arrival, an obvious sense of psychological fear and panic among all the evacuees and involved stakeholders like health care professionals/ staff including doctors, security personnel were identified. Interpersonal communication with the NCDC team followed by individual counselling sessions from the psychiatrist/ psychologist team was a strategy devised for all evacuees. They were inducted for universal infection control measures, personal protective measures, and written instructions on dos and don'ts at the site. The importance of frequent handwashing especially after touching surfaces like door handles, stair railings, bed railings, etc. was instructed for strict compliance. Evacuees were counselled by clinicians for their day-to-day queries.

If needed, a referral was also made to the psychiatrist/ psychologist team. It was also observed that there was a sense of fear among communities in the surrounding villages of the ITBP camp. Counselling/ IEC sessions were conducted in the community to allay their apprehensions. After the counselling sessions, the public was relaxed and accepted it as a matter of national health concern and cooperated. The transmission of COVID-19 was not initiated in the vicinity and surrounding areas of the ITBP campus, as it was not reported.

\section{Sample Collection and Packaging}

For baseline testing, samples (Nasopharyngeal swab and throat swabs) for COVID-19 were collected from all passengers ( 02 batches) and sent with triple-layer packaging maintained in cold chain $\left(2-8^{\circ} \mathrm{C}\right)$ to the recommended laboratory in AIIMS/ NIV, Pune on February 4, 2020. Safe collection \& handling of specimens in the quarantine camp was performed in designated locations as per the documented SOP. Specimen containers used in our Quarantine camp was Viral Transport Medium (VTM vials containing $3 \mathrm{ml}$ medium) with falcon tubes $(50 \mathrm{~mL})$ as a secondary layer of the triple-layer packaging system. Containers were correctly labelled to facilitate proper identification. Specimen request or specification forms were placed in a separate waterproof zip pouch with lock and pasted on the outside walls of the sample transport containers. Specimen data referral form from NIV Pune, authorization letters that identify the specimen for "testing of COVID-2019 - Acute Respiratory Disease" was handed over to ICMR personnel's at AlIMS Delhi for further transport the samples to NIV Pune for diagnostic testing.

\section{Results}

All the collected 406 samples were found negative for COVID-19 at baseline on 07 February 2020 as tested by RTPCR method. Just before the end of the 14-day quarantine period, re-sampling of nasopharyngeal swabs was done (13 and 14 February 2020) and once again sent in cold chain to NIV, Pune for testing. All the 406 samples were again reported to be negative for COVID-19. Evacuees with corona related initial symptoms were immediately directed to 'Super Specialty Isolation Wards' at Safdarjung Hospital, New Delhi.

\section{Discharge of Passengers from Quarantine Facility}

The passengers were discharged on February 17-18, 2020 (114 and 292 respectively) with instructions to selfmonitor their health at their home (home quarantine) for the next 14 days and immediately report to their District Surveillance Officer (DSO), in case of development of symptoms suggestive of COVID-19. Written instructions were handed over to each evacuee. The District Surveillance Units (DSO) and State Surveillance Units (SSO) were provided with contact details of the evacuees to conduct active surveillance for the next 14 days under intimation to the Central Surveillance Unit, IDSP (NCDC). A list of all the DSO/SSO located in respective states/ UT in India was provided to all the evacuees.

\section{Terminal Disinfection and Decontamination Procedures}

Quarantine facility terminal disinfection procedures were carried out on February 18-19, 2020 under the supervision of the NCDC team. Cleaning/ decontamination was done using the proper personal protective equipment (PPE) and adopting a three-bucket system as prescribed in the SOP (Annexure).

Spraying of $1 \%$ sodium hypochlorite working solution 
(dilution 1:4 from an initial concentration of 4\%) was done on all the surfaces (protecting electrical points/appliances). This was followed by cleaning with a neutral detergent used for removing traces formed by hypochlorite solution. While cleaning, windows were opened for proper ventilation for cleaning personnel.

All frequently touched areas, such as all accessible surfaces of walls and windows, the toilet bowl and bathroom surfaces, were also carefully cleaned. All textiles (e.g. pillow linens, curtains, etc.) were first treated with $1 \%$ hypochlorite spray and then, packed and sent to get washed in laundry using a hot-water cycle $\left(90^{\circ} \mathrm{C}\right)$ with laundry detergent. $1 \%$ hypochlorite solution was also sprayed in the PPE doffing area and discard area twice on daily basis. Mattresses/ pillows after spraying with $1 \%$ hypochlorite, were allowed to get dry (both sides) in bright sunlight for up to 3 hours each.

\section{Discussion}

Quarantine Preparedness among other countries is discussed here:

Screening wards in India (Coronavirus in India, February 2020). ${ }^{3}$

In Delhi: Manesar camp was already monitoring those who came from China. Ram Manohar Lohia, AlIMS and Safdarjung hospitals in the capital also readied isolation facilities.

In Mumbai: Two Mumbai hospitals namely, Kasturba hospital and Pune's Naidu hospital- were dedicated for suspected patients in the state.

In Karnataka: The state government has placed border districts of Dakshina Kannada, Kodagu, Chamarajnagar and Mysuru under quarantine for novel coronavirus.

China built over 20 mass quarantine centers in Wuhan city. The quarantine centers are called fan tsungyuen (ph), or cabin hospital. They're modeled after military-style barrack housing, and they're not glamorous - rows of beds in repurposed stadiums and exhibition centers staffed by a handful of nurses and doctors (Emily feng 2020). ${ }^{4}$

Russia temporarily barred Chinese nationals from entering the country to curb the spread of the virus, but welcomes Russian nationals who returned home with order of strict 14-day home quarantine even in the absence of symptoms. As part of the quarantine process, Moscow uses facial recognition technology to ensure people adhering to the order of home quarantine. ${ }^{5}$

Singapore announced that three hostels each from the National University of Singapore (NUS), Nanyang Technological University (NTU) and Singapore Management University (SMU) will be used as quarantine facilities (Outward Bound Singapore, 2020). ${ }^{6}$
Japan responded by developing a cruise ship into quarantine facility named Diamond princess cruise. Cruise quarantine has kept some 3700 passengers and crew confined on the ship since February 5, 2020 in an effort to limit the entry of the virus into Japan. However, a Japanese scientist, Kentaro Iwata, Japanese infectious disease specialist of Kobe University has harshly criticized the way Japan's government has handled the COVID-19 crisis aboard a luxury cruise ship docked in Yokohama. Conditions on board the Diamond Princess were "violating all infection control principles" and "completely chaotic," (Scientist decries, 2020). ${ }^{7}$

U.S: Quarantine Stations are located at 20 ports of entry and land-border crossings where international travelers arrive. They are staffed with quarantine medical and public health officers from CDC. These health officers decide whether ill persons can enter the United States and what measures should be taken to prevent the spread of infectious diseases (U.S. Quarantine Stations, 2020). ${ }^{8}$

Italy: On February 22, 2020 the government announced a new decree imposing the quarantine of more than 50,000 people from 11 different municipalities in Northern Italy the quarantine zones were called the Red Zones and the areas in Lombardy and Veneto outside of them were called the Yellow Zones (Italian Churches, 2020). ${ }^{9}$

\section{Conclusion}

It is essential to review the preparedness of the facility in terms of infrastructure, logistics, and deploy adequate manpower with experts from different specialities for establishing infection prevention control measures in the facility. Prior Standard Operative Procedures (SOP) formation and training of healthcare staff and other workers help in better coordination and in building confidence among health workers. Availability of necessary facilities i.e., food, laundry, recreation facilities, psychosocial support \& regular interpersonal communication helps to reduce the anxiety and fear among the quarantined. Ownership among the paramedical/ housekeeping staff helps to get work done effectively. The role of a psychiatrist/ clinical psychologist is important in managing effective communication among the evacuees and healthcare givers. The role of a microbiologist is also important in limiting/ containing the infection, its prevention and control. Daily update of the worldwide situation needs to be updated for the overall management of disease progression and to study transmission dynamics. The role of public health experts and an epidemiologist is critical to analyze the disease epidemiology and provide most valuable inputs in enhancing public health measures, risk communication and community engagement for managing the quarantine facility. Effective teamwork with better coordination among different teams is the most important for the successful management of a quarantine facility. Most importantly, 
early preparedness and regular monitoring of the facility is essential for successful quarantine. Lessons learned from these procedures were later used for developing quarantine facilities across India. All the recommendations were found to be effective for successfully quarantining the evacuees in the present outbreak of COVID-19.

\section{Acknowledgement}

The authors are thankful to Dr AP Joshi and his team at ITBP Quarantine Center at Delhi for all the support given, and DGHS and other authorities for the assistance and for fulfilling other necessary requirements related to the first quarantine work.

\section{Author Contributions}

Himanshu Vashistha, Ajit Shewale, and Rameshwar Sorokhaibam designed the facility, Ajit shewale and Himanshu Vashistha wrote the manuscript with equal contribution. Meera Dhuria, Sudhir Kumar Jain, and Sujeet Singh have reviewed the manuscript. All the authors have read and agreed to the published version of the manuscript.

\section{Funding}

This work was carried out by National Centre for Disease Control (NCDC), and was supported by the EMR division, MoHFW at ITBP Chhawla Centre, Delhi.

\section{Conflicts of Interest: None \\ References}

1. World Health Organization [Internet]. WHO declares global health emergency; 2020 [cited 2020 Feb 27]. Available from: https://www.who.int/emergencies/ diseases/novel-coronavirus-2019/events-as-theyhappen

2. World Health Organization [Internet]. WHO 2019-nCoV situation report 1; 2020 [cited 2020 Feb 28]. Available from: https://www.who.int/docs/default-source/ coronaviruse/situation-reports/20200121-sitrep-12019-ncov.pdf?sfvrsn=20a99c10_4

3. The Economic Times [Internet]. Coronavirus in India: What is happening and what you should know; 2020 [cited 2020 Feb 28]. Available from: https:// economictimes.indiatimes.com/news/international/ world-news/coronavirus-in-india-what-is-happeningand-what-you-should-know/articleshow/73978271. cms?utm_source=contentofinterest \&utm medium=text\&utm_campaign=cppst

4. Feng E. China has built over 20 mass quarantine centers for coronavirus patients in Wuhan [Internet]; 2020 [cited 2020 Feb 28]. Available from: https://www.npr. org/2020/02/24/808995258/china-has-built-over-20mass-quarantine-centers-for-coronavirus-patients-inwuha

5. The Economic Times [Internet]. Moscow deploys facial recognition technology to coronavirus quarantine; 2020 [cited 2020 Feb 27]. Available from: https://economictimes.indiatimes.com/news/ international/world-news/moscow-deploysfacial-recognition-technology-for-coronavirusquarantine/articleshow/74244745.cms?utm_ source=contentofinterest\&utm_medium=text\&utm_ campaign $=$ cppst

6. CAN [Internet]. Outward bound Singapore camps on Pulau Ubin to be used as quarantine facility; 2020 [cited 2020 Feb 28]. Available from: https://www. channelnewsasia.com/news/singapore/wuhanvirus-singapore-obs-camp-pulau-ubin-quarantinefacility-12360724

7. Science [Internet]. Scientist decries 'completely chaotic' conditions on cruise ship Japan quarantined after viral outbreak; 2020 [ctied 2020 Feb 28]. Available from: https://www.sciencemag.org/news/2020/02/ scientist-decries-completely-chaotic-conditions-cruiseship-japan-quarantined-after

8. Centers for Disease Control and Prevention [Internet]. Quarantine stations: a comprehensive quarantine system; 2020 [cited 2020 Feb 28]. Available from: https://www.cdc.gov/quarantine/quarantinestations. html

9. WSJ [Internet]. Italian churches go into quarantine; 2020 [cited 2020 Feb 28]. Available from: https:// www.wsj.com/articles/italian-churches-go-intoquarantine-11582847215 la Repubblica [Internet]. Coronavirus, in dieci comuni Lombardi: 50 mila persone costrette a restare in casa. Quarantena all'ospedale milanese di Baggio; 2020 [cited 2020 Feb 2020]. 


\section{Annexure}

\section{Annexure I: Daily Reporting Format}

\begin{tabular}{|c|c|c|c|c|c|c|c|c|c|c|c|}
\hline \multicolumn{12}{|c|}{$\begin{array}{l}\text { Name of the Centre: Address: } \\
\text { Centre In Charge: } \\
\text { Contact No: }\end{array}$} \\
\hline $\begin{array}{l}\text { 2 } \\
\text { vi }\end{array}$ & 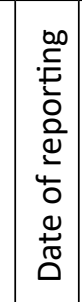 & 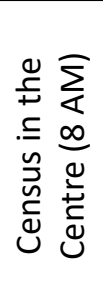 & 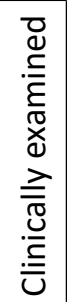 & 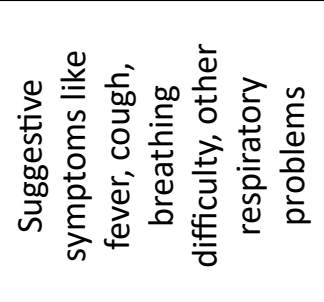 & 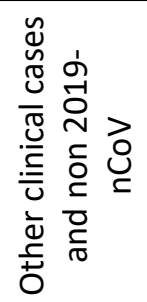 & 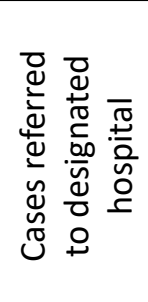 & 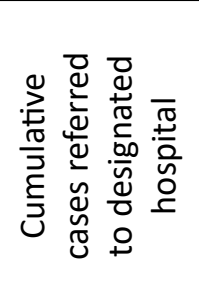 & 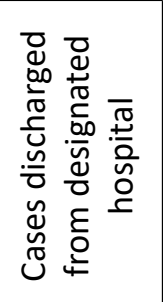 & 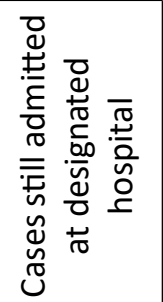 & 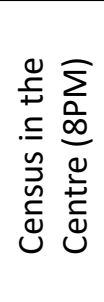 & 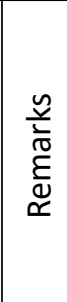 \\
\hline
\end{tabular}

\section{Annexure 2: Standard Operative Procedures for Medical Personnel}

The shift duties of the doctors may be as mentioned below:

Morning: 8:00 AM to 2:00 PM Afternoon : 2:00 PM to 8:00 PM

Night: 8:00 PM to 8:00 AM (next day)

General instructions for medical doctors from designated hospital(s) for performing their duty at the quarantine facility may be as mentioned below:

1. The name of the duty officers and duty roster to be displayed in the control room.

2. Each team to follow the procedure mentioned below:

- The resident doctors on duty will report to the centre at the reporting time and mark attendance in the register.

- After that, they will go to the clinical area to examine the quarantined people in the centre.

- The doctors on working duty will team up with medical officers from the quarantine facility to form a paired team (one from the hospital and another from the quarantine facility) to examine the cases.

- They will examine and assess the patients and report to the In-charge of the quarantine facility.

- They will take care of the infection control/ protective measures while examining the persons and follow guidelines placed at the door for safety/ infection control measures.

- If any symptomatic case/ additional symptoms are observed/ reported, they should be discussed with the In-charge of the quarantine facility for referral to the designated hospital, if required.

- A complete examination of all patients and report before 12 noon on the same day and handing over the report to the Office In-charge will be done for onward transmission to the Ministry.

- No team will leave till the relieving team arrived.

- The team will hand over this information to the relieving team.

- The team will leave the quarantine facility with due permission of In-charge of the quarantine facility.

- If any doctor has not reported due to unavoidable circumstances, the present available team will inform the concerned authority of the designated hospital for substitute.

- In case any patient needs to be transferred due to any eventuality to the referral centre, the senior-most doctor will accompany the ALS Ambulance to take care of the patient till he/ she reaches and is handed over to the centre.

- The medical team may take help of the psychiatric/ counsellor team if required, for psychosocial support.

- The team will work in harmony with the quarantine facility medical team.

- The senior-most doctor on duty from the designated hospital will take decision of the clinical management.

\section{Annexure 3: Standard Operative Procedures for Nursing Officer (Supervisor)}

- Maintain a log of medical professionals/ staff entering/ exiting in the quarantine facility, where the quarantine people are housed.

- A designated nursing officer has to ensure that the incoming officers/ staff to the quarantine building are wearing appropriate PPE, and they are aware of universal infection control precautions (handwashing (alcohol/sanitisers or soap + water) mask, gloves, PPE). 
- $\quad$ After this, he/ she will allow the person to enter.

- The PPE kits doffed off by the outgoing medical professionals need to be disposed of in the yellow bag and hand sanitisation should be ensured after disposing of the PPE.

- Yellow bags containing the infected materials placed in the nearby gate should be disposed of daily as per the Biomedical Waste Management Rules.

- The dustbins should be covered at all times. This should be ensured by the Nursing officer. If required, disinfection has to be done as advised.

- Black bags (municipal wastes) - to be disposed of after proper packaging daily as per the Biomedical Waste Management Rules.

\section{Annexure 4: Standard Operative Procedures for Movement of Health Professionals and Support Staff inside the Quarantine Facility}

- The movements of health professionals are to be monitored at three vital points considering the control of infection for the prevailing disease-

1. Control room:

- Health professionals and support staff need to be made aware and trained in the correct procedure of wearing masks and gloves.

- $\quad$ They need to be trained to follow the infection control measures as instructed including handwashing with soap and water and sanitising with alcohol-based sanitisers, cough etiquettes, donning and doffing of PPE etc. before entering the quarantine facility.

2. Main Sentry post: To enter the quarantine facility, the personnel should wear the mask correctly.

3. Nursing Station at Quarantine building (ground floor):

- Registration of name with time and purpose for entering the building will be ensured.

- PPE will be donned here.

- The Nursing officer will check and ensure strict and correct wearing of PPE before entering the main quarantine area.

- After coming out from the main quarantine area, PPE will be doffed properly and placed in the designated bin for infective material (yellow bag).

- The hands will be sanitised before exiting the quarantine area.

- Mobile phones usage will not be allowed inside the building.

- Names of doctors will be written on the PPE with a permanent marker for identification.

\section{Annexure 5: Standard Operative Procedures for Security Personnel at Quarantine Facility}

- $\quad$ For security purposes, ensure 24 hours manning of the post of the quarantine facility.

- The person manning the area must be trained and instructed to wear masks and gloves during the duty period.

- Instructions for infection control measures like handwashing etc. should be properly briefed.

- Doctors/ nursing staff/ supporting staff/ others entering the quarantine area should wear appropriate PPE before entering the quarantine centres.

- Log of those entering/ exiting the quarantine facility should be maintained. Only those having a specific purpose inside the quarantine facility should be allowed to enter.

- The log should be put up daily to the controlling authority.

- The security guard should have a whistle to give signals to people to not come near the quarantine facility if they do not have any purpose to visit it.

- He should report immediately to the Officer In-charge controlling the security of the quarantine facility, if anybody does not follow the instructions as directed.

- The security personnel should not leave after completing his shift till his reliever reports for duty.

- The Officer In-charge controlling the security of the quarantine facility should supervise the duty roster and roles and responsibilities of all the personnel deployed at the quarantine area for smooth functioning. 